\title{
Numerical modelling of dynamic testing for rock reinforcement used in underground excavations
}

\author{
E Marambio University of Chile, Chile \\ JA Vallejos University of Chile, Chile \\ L Burgos University of Chile, Chile \\ C Gonzalez MIRARCO Mining Innovation, Canada \\ L Castro Compañía Siderúrgica Huachipato, Chile \\ JP Saure Compañía Siderúrgica Huachipato, Chile \\ J Urzúa Teiko Ingeniería Ltda., Chile
}

\begin{abstract}
As mines have expanded due to increased depth, new challenges have appeared for mining engineers. High-stress environments, where there are rockburst events caused by energy release, have become especially interesting in terms of geomechanics and have prompted changes in conventional designs, demanding more research into how underground excavations absorb dynamic impacts.

For these underground excavations, the development of new reinforcement elements capable of both resisting dynamic loads and yielding in the process without failing has advanced in the last 30 years due to studies and testing programs carried out by recognised institutions. However, executing these testing programs implies a high cost in time and validation. Hence, a limited number of these have been completed. In this context, numerical modelling to represent the performance of the process and enhance laboratory testing has become increasingly necessary and relevant.

In this paper, a numerical modelling methodology based on the finite difference method has been applied in order to predict the behaviour of threadbar, commonly used in Chilean mining as reinforcement in underground excavations, in dynamic load testing. Accordingly, a comparison and calibration of the numerical model with laboratory-scale dynamic tests from previous research is presented.
\end{abstract}

Keywords: dynamic testing, reinforcement, numerical modelling, rockburst, high stress, underground mining

\section{Introduction}

New technologies related to the mining industry have been developed in the last century as the mining industry has expanded. These technological developments have responded not only to production and planning issues, but also to problems related to physical phenomena present in the field that hinder mining progress. In high-stress underground mining, rockburst events have increased internationally in the last few years prompting research into this phenomenon. Efforts to understand, quantify damage, and mitigate the effects of these events have increased due to studies carried out by recognised institutions within the mining industry, and based on the work performed by the Canadian RockBurst Research Program (Kaiser et al. 1996; Cai \& Kaiser 2018).

One focus of study has been on how underground excavations are supported and how support systems absorb dynamic impacts. Several researchers have dedicated their efforts to the study of the reinforcement and retainment elements that compose the support system in an attempt to improve the standard designs widely used and initially conceived for static load resistance. 
Institutions such as the Canmet Mining and Mineral Sciences Laboratories (Canmet-MMSL) of Canada and the Western Australia School of Mines (WASM) have been studying the behaviour of reinforcement and retainment elements under dynamic loads. Their studies have evolved from simply comparing loads to analysing the capacity of support system elements to absorb energy from impacts and deform during the process. Through laboratory-scale testing representative of in situ conditions, the aforementioned institutions have worked to quantify the deformation and absorption of energy of these elements, resulting in comparative parameters and an adaptable design under dynamic loads.

However, laboratory-scale testing involves a high cost in preparation time and validation. Hence, a limited number of these tests are carried out. Numerical modelling is an alternative that, in addition to enhancing the results from laboratory testing, should be useful to explain the deformation and absorption process. Yi and Kaiser (1994a), Tannant et al. (1995), Ansell (1999, 2005), Thompson et al. (2004), and St-Pierre (2007) have modelled the dynamic behaviour of reinforcement elements in laboratory-scale testing centred around load-displacement relationships. The role of grout, however, has not been fully incorporated into these models even though the grout-rockbolt interface has been shown to be where the failure of most reinforcement elements occurs in situ.

In Chile, in the process of developing a new laboratory-scale dynamic testing facility supported by the University of Chile and MIRARCO, using a mechanism similar to Canmet-MMSL's, several studies have been conducted in which numerical modelling is taken into account as an important part of the process. Here, a methodology is proposed to numerically model the process of laboratory-scale dynamic testing of reinforcement elements, i.e. rockbolts plus grouting. Based on the finite difference method, a model with a specific focus on the threadbar (also known as rebar or gewibar) was developed, which is widely used as rock reinforcement in Chilean underground mining and globally.

\section{Problem conceptualisation and model components}

At the present time, there are two laboratory testing facilities of dynamic conditions for rock reinforcement recognised by the industry. The first started between 1992 and 1994 by Yi and Kaiser under the Canadian Rockburst Research Program (Canmet-MMSL facility), and the second was started in 2004 by Player and Thompson with the support of the Minerals and Research Institute of Western Australia (WASM facility). The difference between the Canmet-MMSL dynamic testing facility and the WASM dynamic testing facility lies in the principle used for their experimental tests.

The Canmet-MMSL facility applies the energy transfer principle, whereas the WASM facility applies the momentum transfer concept. In this sense, the Canmet-MMSL facility transforms potential energy into kinetic energy through the fall of a mass from a given height that impacts the lower end of a rockbolt embedded in a pipe with grout causing deformation and possible failure (simulating the in situ conditions).

On the other hand, the WASM dynamic facility operates by measuring the effects of the fall of a complete system including a beam, the reinforcement, and a loading mass. The system falls freely until a point where it is abruptly stopped by buffers. Under this condition, the rockbolt continues to move and could lengthen and/or slip, and possibly fail. Figure 1 shows the Canmet-MMSL dynamic testing facility set-up, while Figure 2 shows the dynamic testing facility developed by WASM. 

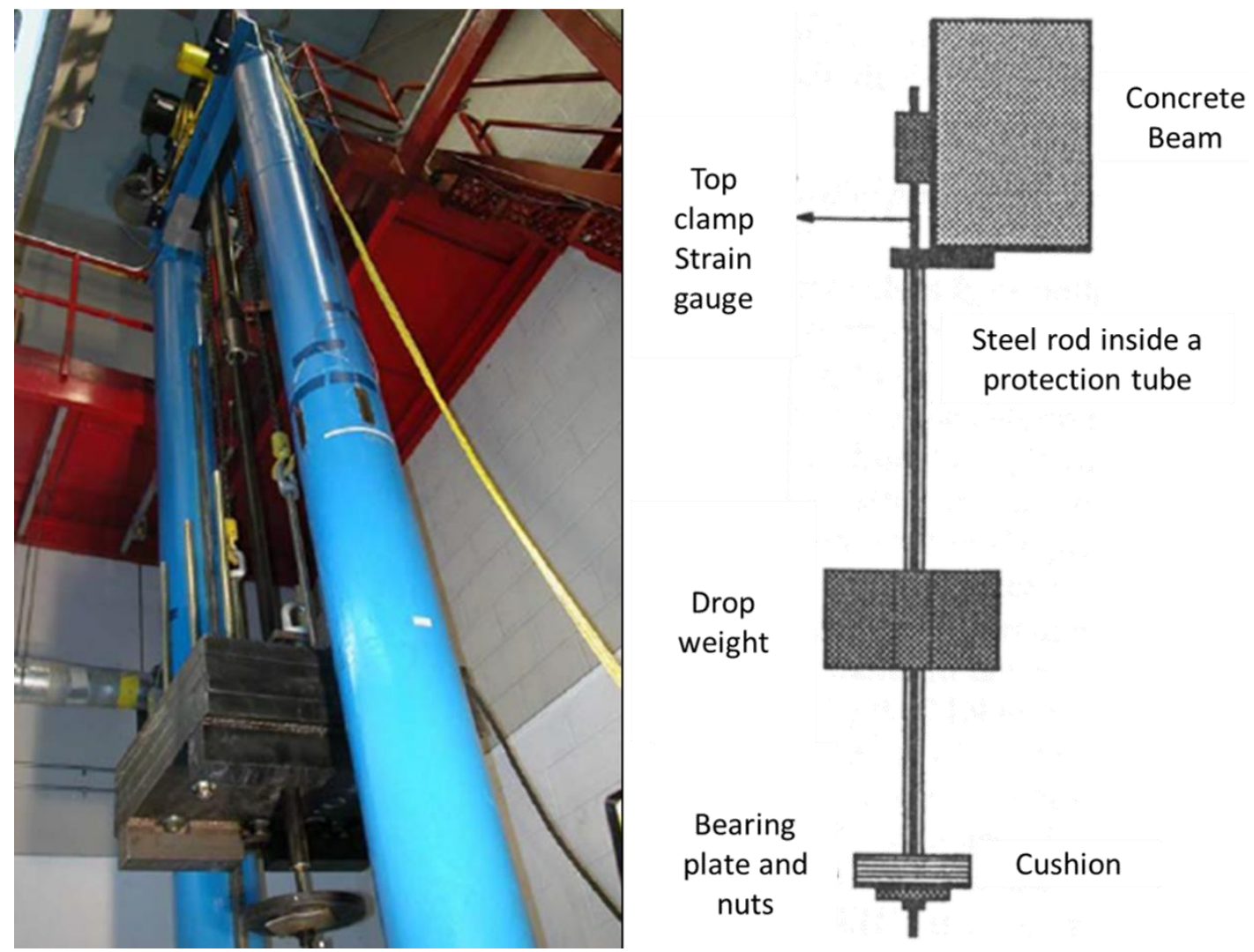

Figure 1 Set-up of the dynamic testing facility at Canmet-MMSL (after Yi \& Kaiser 1992, 1994b)
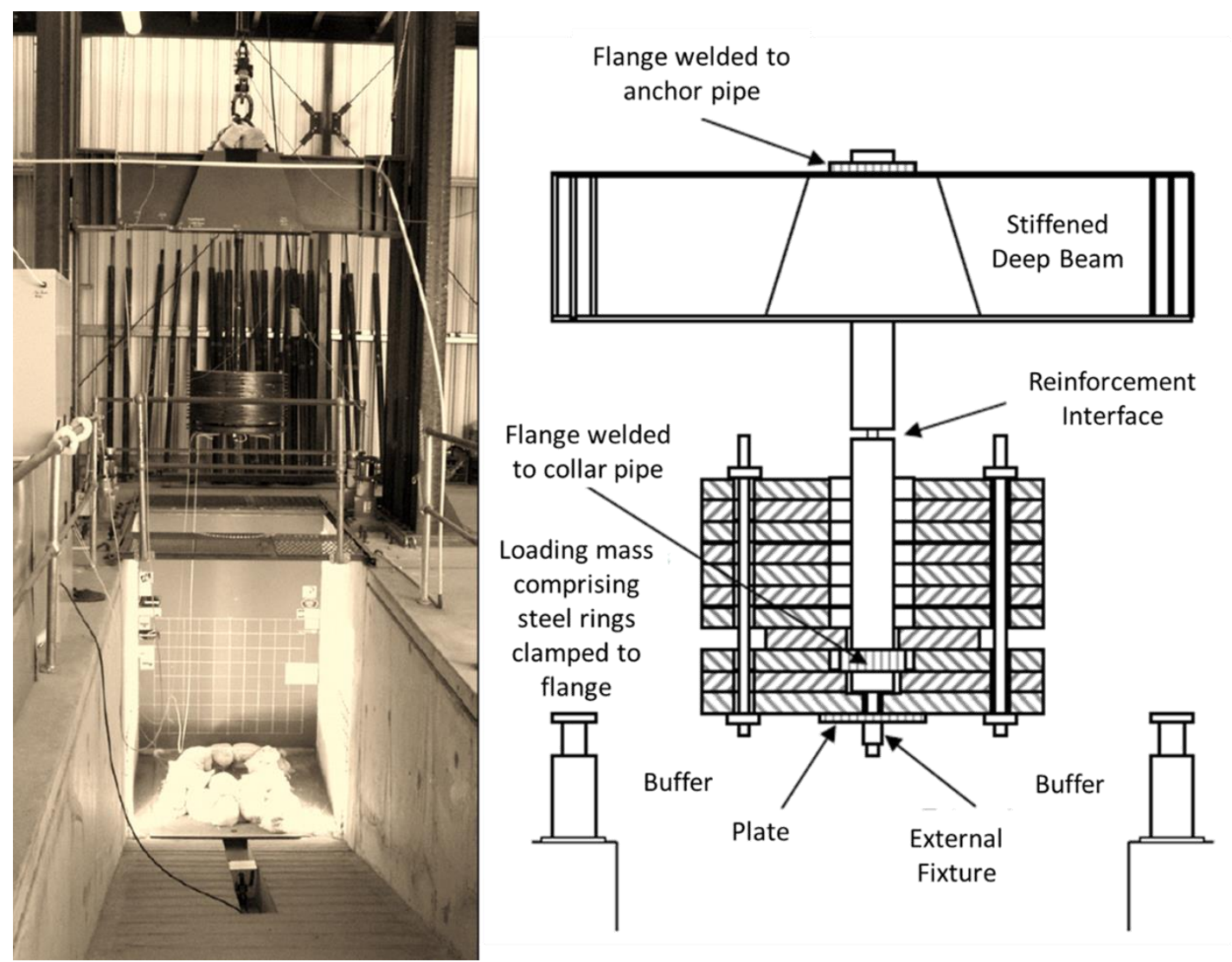

Figure 2 Set-up of the dynamic testing facility at WASM (after Player et al. 2004, 2008) 
The development and construction of a future laboratory-scale dynamic testing facility in Chile supported by the University of Chile and MIRARCO with a mechanism similar to Canmet-MMSL's motivated the development of the numerical model as illustrated in Figure 3(a). In addition, several authors have questioned the effects of dynamic loads on rock reinforcements (Doucet \& Gradnik 2010; Wu et al. 2010; Li \& Doucet 2012; Doucet \& Voyzelle 2012) and those questions inspired the numerical model described here.

(a)

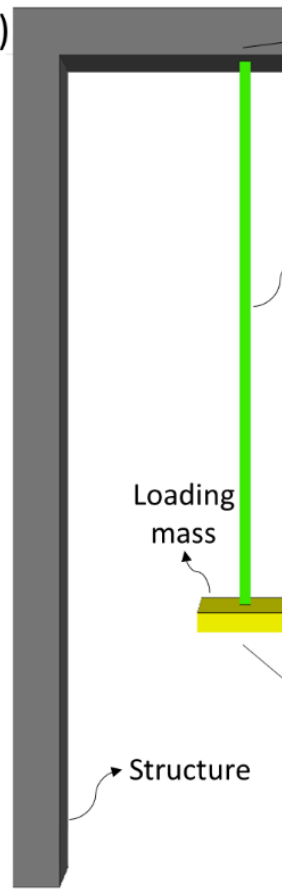

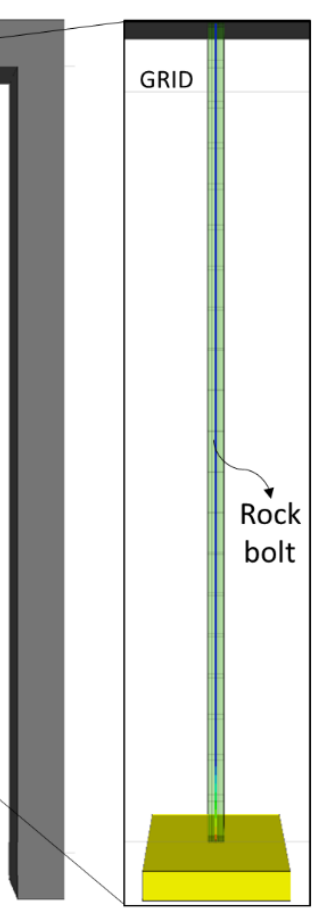

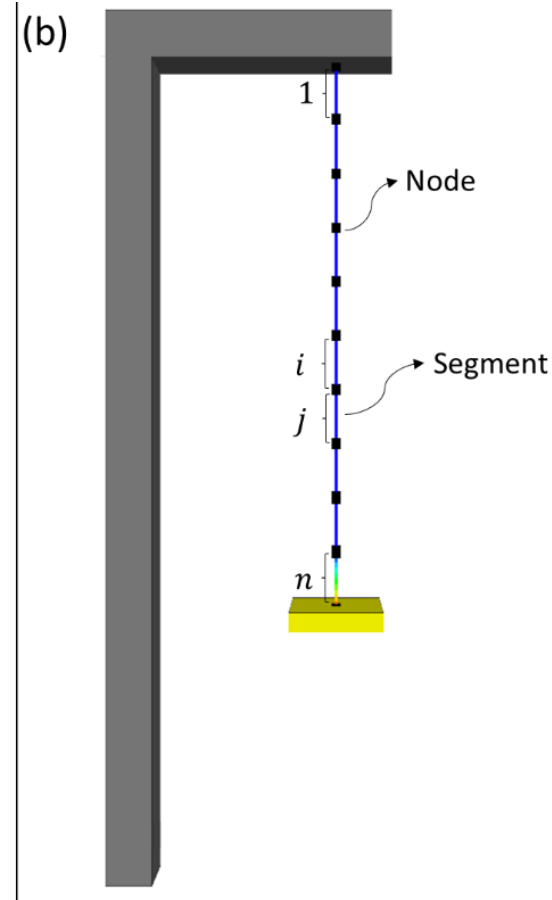

Figure 3 (a) Model scheme in FLAC3D software; and, (b) Reinforcement element represented by segments joined by nodes

Most importantly, the threadbar response was selected in this first approach because of the urgent need to improve its performance under the dynamic conditions found in Chilean underground mining. Regrettably, due to restricted availability of threadbar test results from Canmet-MMSL, only a limited comparison of results could be made with laboratory-scale dynamic test results from WASM, which are available in the literature (Player \& Cordova 2009; Player et al. 2009). Thus, the focus of the model is on the methodology rather than on the comparison with laboratory-scale results. The model will be discussed further in Section 4 of this paper.

This model utilises the finite difference software FLAC3D (Itasca Consulting Group Inc. 2012), widely known in the geomechanical and geotechnical industry, to characterise the system by:

- A threadbar represented in the model by a discretised cable structural element that responds to the tension through a perfect plastic constitutive model.

- A grid that envelops the threadbar represents the grout and the steel pipe in which the rockbolt is inserted in the laboratory-scale dynamic tests. However, only the grout behaviour is taken into account.

- A loading mass represented by a geometric element, which is released in freefall along the threadbar before the impact and after the impact is joined to its final discretised element emulating the dynamic impact generated in the Canmet-MMSL laboratory-scale dynamic testing facility.

- A structure that supports the system in which the dynamic testing is carried out. 


\section{$3 \quad$ Numerical modelling of the dynamic testing for rock reinforcements}

In recent years, various efforts have been made to numerically represent the behaviour of dynamic tests for reinforcement elements used in underground excavations. Two approaches have been widely used within the computational mathematical area for the representation of this problem; the lumped-mass models and the dynamic deformation models in a continuum media.

Lumped-mass models, which describe the reinforcement elements as discrete masses in series connected to each other by springs and dampers, have been used in models proposed since the beginning of dynamic study programs for reinforcement elements. Tannant et al. (1995) were early proponents of such a model for the Canmet-MMSL test facility within the Rockburst Research Program of Canada. Thompson et al. (2004) used a similar model to describe the reinforcement behaviour in the WASM test facility. The most recent work that involved this approach has been presented by St-Pierre (2007) in his master's thesis, in which the cone bolt dynamic behaviour obtained at the Canmet-MMSL facility was numerically modelled.

Dynamic deformation models use discrete elements to describe the behaviour of the reinforcement element as a continuous and deformable medium. In this approach, stress and deformation waves characterise the material behaviour in the elastic and plastic ranges through the propagation of the discretised elements in the medium. Ansell $(1999,2005)$ reviewed representative models of response under dynamic loads through this approach. Yi \& Kaiser (1994a) also used these models to describe the wave behaviour inside the reinforcement elements with this approach.

It is important to note that dynamic deformation models and lumped-mass models have different objectives. The dynamic deformation models are more detail oriented and focus on resolving problems related to specific components of a system, whereas lumped-mass models are more global and produce solutions involving the complete system. The approach used in this paper corresponds to the lumped-mass approach, in which the reinforcement element is represented by secondary elements (segments) joined together by nodes (Figure 3(b)). The lumped-mass approach was chosen based on a more global objective to replicate the combined response of the rockbolt and the grout in the dynamic testing facilities, rather than to describe the behaviour of the internal waves in the elements.

\subsection{Governing equations of motion}

Diverse models that characterise the dynamic structures under certain applied force use resolution schemes in which the whole system is simplified to be described through a damped oscillator. In this sense, the equations that describe the process are well known, as is their solution. However, the complexity of these systems lies in how the conditions of stiffness and damping are applied, incorporating difficulty in representing the real conditions of the problem.

To solve the numerical model, the system is divided into two secondary problems. The first problem is described for the freefall of the mass used in the dynamic test until it impacts the plate (damping cushion in the current test) at a particular time of impact $\left(t_{i}\right)$. The second problem is in the interest of modelling, and it is after the moment of impact, when the mass begins to move along with the rockbolt, stretching it or sliding it until possible failure. A schematic of the secondary problem in the numerical model is illustrated in Figure 4.

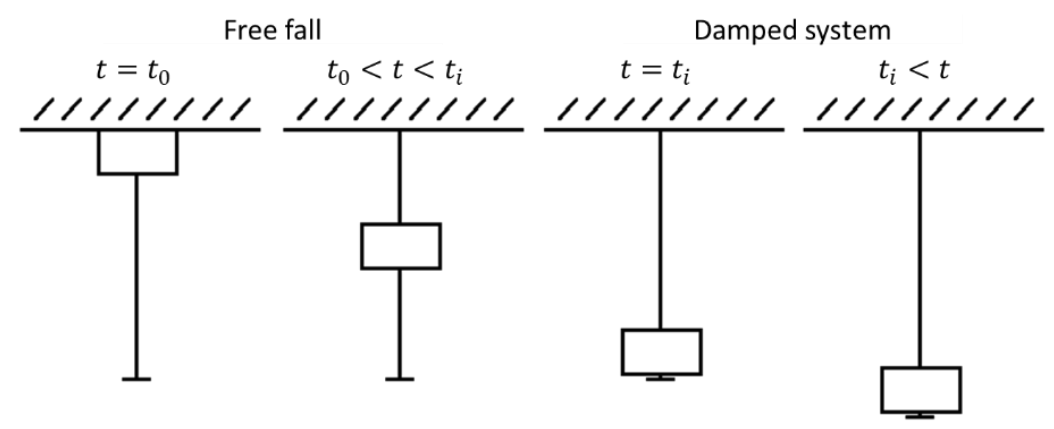

Figure 4 Secondary problems of the model for different moments of time 
After impacting the mass with the plate, the model is characterised as a simplified problem by the free-body diagram in Figure 5. Therefore, the system can be represented by two differential equations, in which the first describes the motion of the rockbolt and the second the motion of the grout, as presented in Equations 1 and 2, respectively. A similar scheme was shown by St-Pierre (2007) in the development of his model for the cone bolt reinforcement element.

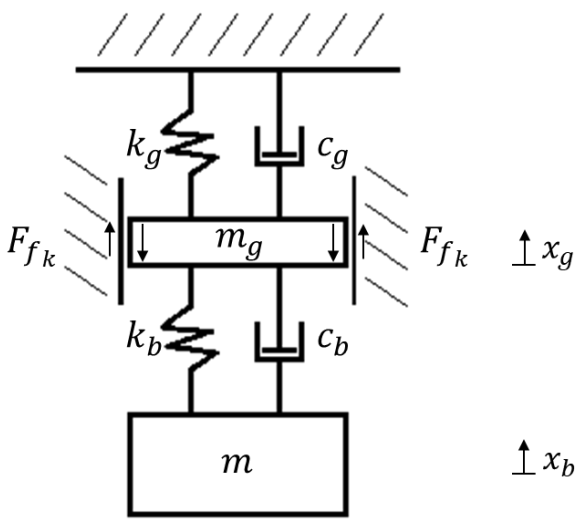

Figure 5 Free-body diagram of the model (after St-Pierre 2007)

$$
\begin{gathered}
m \ddot{x}_{b}+c_{b}\left(\dot{x}_{b}-\dot{x}_{g}\right)+k_{b}\left(x_{b}-x_{g}\right)-F_{f_{k}}+m g=0 \\
m_{g} \ddot{x}_{g}-c_{b}\left(\dot{x}_{b}-\dot{x}_{g}\right)-k_{b}\left(x_{b}-x_{g}\right)-c_{g} \dot{x}_{g}-k_{g} x_{g}+F_{f_{k}}=0
\end{gathered}
$$

where:

$$
\begin{aligned}
& m \quad=\text { loading mass used in the dynamic test. } \\
& m_{g} \quad=\text { grout mass. } \\
& g \quad=\text { gravity. } \\
& k_{b}, k_{g}=\text { stiffness of rockbolt and grout, respectively. } \\
& c_{b}, c_{g}=\text { viscous damping of rockbolt and grout, respectively. } \\
& x_{b}, x_{g}=\text { displacement of rockbolt and grout, respectively. } \\
& \dot{x}_{b}, \dot{x}_{g}=\text { velocity of rockbolt and grout, respectively. } \\
& \ddot{x}_{b}, \ddot{x}_{g}=\text { acceleration of rockbolt and grout, respectively. } \\
& F_{f_{k}}=\text { friction force representing the contact between rockbolt and grout. }
\end{aligned}
$$

The motion equations are solved by an iterative numerical method - explicit in time combined with the unbalanced force criteria from FLAC3D. Notice that the mass of the rockbolt $\left(m_{b}\right)$ in Equation 1 and grout weight $\left(m_{g} g\right)$ in Equation 2 are negligible in comparison with the loading mass of the dynamic test $(m)$, and therefore are not taken into account in motion equations.

The stiffness of the rockbolt and the grout shown in Equations 1 and 2 are approximated by their equivalent stiffness for systems connected in series (Rao \& Yap 2011). Furthermore, the viscous damping of the rockbolt and the grout shown in Equations 1 and 2 are proportional to their respective masses and stiffness, commonly known as classical damping (Rayleigh 1877), described by Equation 3. 


$$
\begin{aligned}
& c_{b}=a_{0_{b}} m_{b}+a_{1_{b}} k_{b} \\
& c_{g}=a_{0} m_{g}+a_{1 g} k_{g} \\
& a_{0_{b}}=2 \omega_{1_{b}} \xi_{1_{b}}-a_{1_{b}} \omega_{1_{b}}^{2} \quad a_{1_{b}}=\frac{2\left(\omega_{2_{b}} \xi_{2_{b}}-\omega_{1_{b}} \xi_{1_{b}}\right)}{\omega_{2_{b}}^{2}-\omega_{1_{b}}^{2}} \\
& a_{0_{g}}=2 \omega_{1 g} \xi_{1 g}-a_{1 g} \omega_{1_{g}}^{2} \quad a_{1 g}=\frac{2\left(\omega_{2 g} \xi_{2 g}-\omega_{1 g} \xi_{1 g}\right)}{\omega_{2_{g}}^{2}-\omega_{1_{g}}^{2}}
\end{aligned}
$$

where:

$$
\begin{aligned}
& c_{b}, c_{g}=\text { viscous damping of rockbolt and grout, respectively. } \\
& a_{0_{b}}, a_{0 g}=\text { mass proportional damping coefficient of rockbolt and grout, respectively. } \\
& a_{1_{b}}, a_{1 g}=\text { stiffness proportional damping coefficient of rockbolt and grout, respectively. } \\
& k_{b}, k_{g}=\text { stiffness of rockbolt and grout, respectively. } \\
& m_{b}, m_{g}=\text { mass of rockbolt and grout, respectively. } \\
& \omega_{1_{b}}, \omega_{2_{b}}=\text { first and second normal mode of vibration for rockbolt, respectively. } \\
& \omega_{1 g^{\prime}}, \omega_{2 g}=\text { first and second normal mode of vibration for grout, respectively. } \\
& \xi_{1_{b},} \xi_{2 b}=\text { first and second damping ratio of rockbolt, respectively. } \\
& \xi_{1 g}, \xi_{2 g}=\text { first and second damping ratio of grout, respectively. }
\end{aligned}
$$

\subsection{Materials influence}

The rockbolt properties are well known and each manufacturer shows the properties of the material of its specific rock reinforcement element in their catalogues. However, it is known that steel changes its yield limit and ultimate strength under dynamic loading conditions. According to Malvar and Crawford (1998), these magnitudes can be estimated by the elastic properties of steel scaling through a dynamic increase factor as shown in Equation 4.

$$
\begin{gathered}
D I F=\left(\frac{\dot{\varepsilon}}{10^{-4}}\right)^{\alpha} \\
\alpha_{f_{y}}=0.074-0.040 \frac{f_{y}}{414} \\
\alpha_{f_{u}}=0.019-0.009 \frac{f_{y}}{414}
\end{gathered}
$$

where:

$$
\begin{array}{ll}
D I F & =\text { dynamic increase factor. } \\
\dot{\varepsilon} & =\text { strain rate. } \\
f_{y} & =\text { yield limit of steel in static condition in } \mathrm{MPa} . \\
\alpha_{f_{y^{\prime}}}, \alpha_{f_{u}} & =\text { coefficients for yield limit and ultimate strength of steel. }
\end{array}
$$

The normal modes of vibration for rockbolts can be approximated from a steel bar embedded at one extreme (Den Hartog 1985), as illustrated in Equation 5. 


$$
\omega_{n_{b}}=\frac{\mu_{n}}{2 \pi L^{2}} \sqrt{\frac{E I}{\rho A}}
$$

where:

$\omega_{n_{b}}=\mathrm{n}$ normal mode for rockbolt.

$L \quad=$ length of rockbolt.

$\rho=$ density of rockbolt.

$E \quad=$ Young's modulus of rockbolt.

$I \quad=$ moment of inertia of rockbolt.

$\mu_{n}=$ empirical coefficient for each mode. $\mu_{1} \cong 3.52$ and $\mu_{2} \cong 22$.

A little more difficult to model, due to the less heterogeneous and less isotropic nature of the material, is the grout. Hyett et al. (1992) studied the behaviour of the grout through static tests for cable bolts, commonly known as pull-out tests. Through these tests, it was found that the properties depend mainly on the water-cement ratio used, the length of the embedding, and the radial confinement applied. However, in laboratory-scale testing, in which the borehole is simulated through a steel pipe, the external confinement effect is practically null. Due to the above, the radial stiffness (Hyett et al. 1992) exerted by the pipe that encapsulates the grout appears as a 'radial compression' and is described through Equation 6.

$$
k_{r_{g}}=\frac{2 E}{(1+v)}\left\{\frac{d_{o}^{2}-d_{i}^{2}}{d_{i}\left[(1-2 v) d_{i}^{2}+d_{o}^{2}\right]}\right\}
$$

where:

$$
\begin{aligned}
& k_{r_{g}}=\text { radial stiffness of the encapsulating pipe. } \\
& v \quad=\text { Poisson's ratio of the encapsulating pipe. } \\
& E \quad=\text { Young's modulus of the encapsulating pipe. } \\
& d_{i}, d_{o}=\text { inner and outer radio of the encapsulating pipe, respectively. }
\end{aligned}
$$

On the other hand, to estimate the axial stiffness $\left(k_{g}\right)$ and the cohesive strength $\left(c_{g}\right)$ of the grout, the formulations of St John and Van Dillen (1983), intrinsically present in FLAC3D, were used, as shown in Equation 7.

$$
\begin{gathered}
k_{g} \cong \frac{2 \pi G_{g}}{10 \ln (1+2 t / D)} \\
c_{g}=\pi(D+2 t) \tau_{l} Q_{B} \quad \Rightarrow \quad c_{g} \approx \pi(D) \tau_{l} Q_{B}
\end{gathered}
$$

where:

$$
\begin{array}{ll}
G_{g} & =\text { shear modulus of the grout. } \\
D+2 t & =\text { borehole diameter, equivalent to } d_{i} . \\
\tau_{l} & =\text { shear strength of the grout, estimated as a half of uniaxial compressive strength. } \\
Q_{B} \quad= & \text { bonding quality of grout and rock mass (encapsulating pipe in this case), equal to } 1 \text { for a } \\
& \text { perfect bond. }
\end{array}
$$

Note that since the interface of interest is between the grout and the rockbolt, the cohesive strength equation is evaluated for $D$ instead of $D+2 t$. This is consistent with the in situ experience where the failure of most reinforcement elements occurs in the rockbolt-rout interface rather than the grout-rock interface.

Finally, the normal modes of vibration for the grout are determined by the eigenvalues of the modal matrix, where the values of the normal modes are extrapolated to a damping system, as illustrated by Nilsson (2009). 


\section{$4 \quad$ Results and discussion}

The objective of modelling is to represent the behaviour of an actual support testing system. In this case, the desired result is to replicate the dynamic test response for reinforcement elements used in underground excavation, in particular for the threadbar. Figure 6 shows three temporal stages of the dynamic test model in FLAC3D, demonstrating how the numerical model represents the scheme shown in Figure 4.

Figure 7 shows the comparison between the model (simulated curve) and laboratory-scale dynamic test results from WASM for threadbar with a de-bonded section (Player et al. 2009; Player \& Cordova 2009) for different lengths of reinforcement. In this graph, the similarity between numerical results and laboratory testing results can be appreciated. The parameters and coefficients used in the modelling are summarised in Tables 1 and 2 . In addition, Figure 8 illustrates a numerical example of the force and displacement profiles of a sample of rockbolt of $3.2 \mathrm{~m}$ length at a final time stage of the model, when equilibrium has been reached.

A velocity profile, which is generated by the combined movement of the mass and the reinforcement element found by modelling during the simulation time, corresponds directly to the results observed in laboratory testing. The velocity profile determines the oscillatory curve shape in the yield limit. This curve is consistent with how the dynamic increase factor is calculated, directly depending on the strain rate and thus the velocity profile (Equation 4). However, the basis of the oscillatory curve shape during the yielding condition may be explained by the hysteretic loading profile of the rockbolt when it reaches the dynamic plastic deformation zone. This zone is a result of the deformation of multiple segments, each of which deforms at different intervals producing overlapping responses. Therefore, a more accurate study to verify this explanation is necessary.
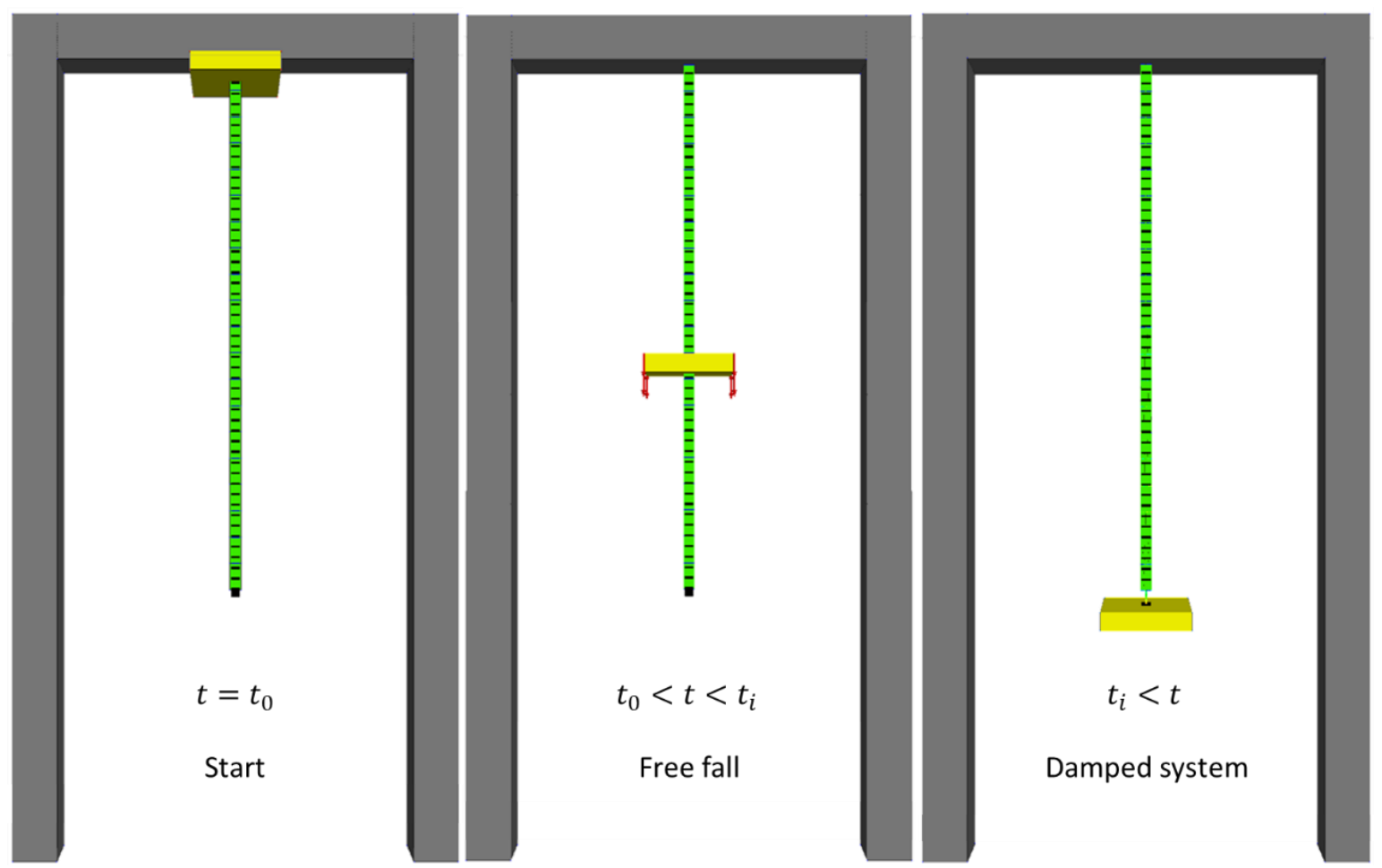

Figure 6 Solve scheme in FLAC3D Software. From left to right, three temporal stages of the numerical model 
(a)

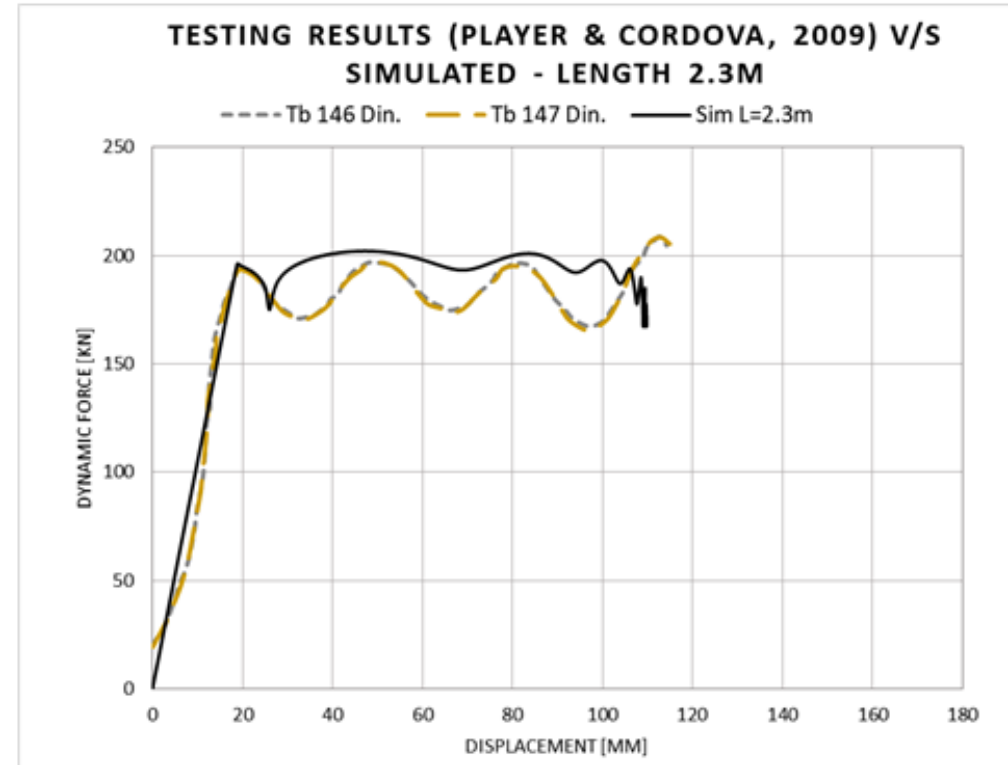

(b)

TESTING RESULTS (PLAYER ET AL., 2009) V/S SIMULATED - LENGTH $3.0 \mathrm{M}$

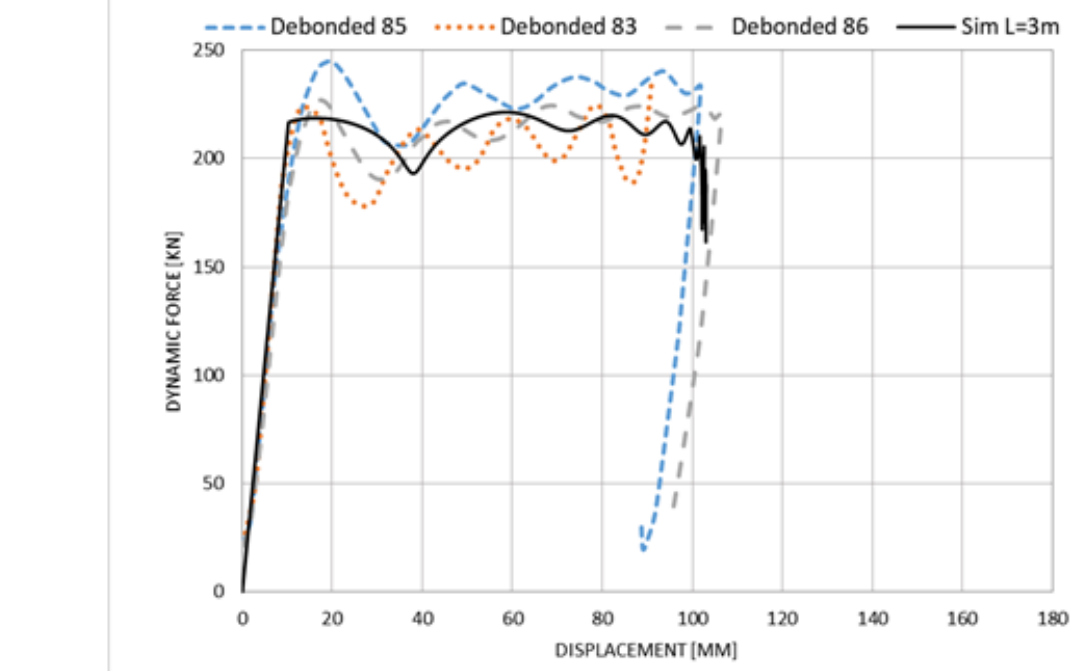

(c)
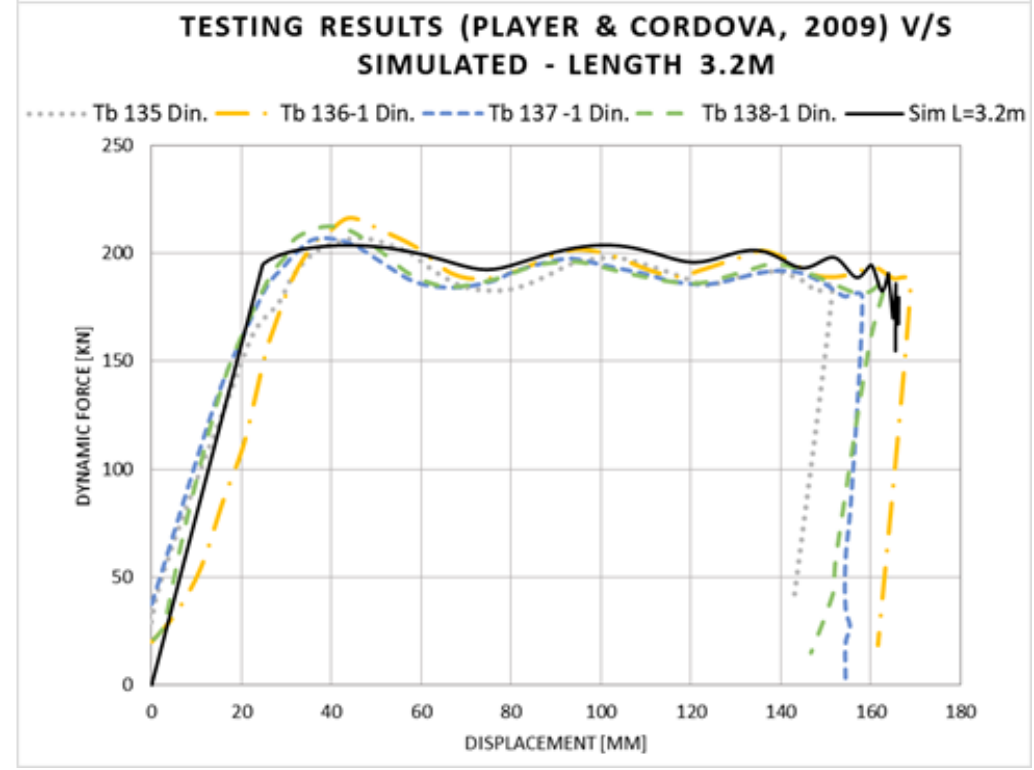

Figure 7 Model response comparison with test results; (a) $2.3 \mathrm{~m}$ rockbolt length; (b) $3 \mathrm{~m}$ rockbolt length; and, (c) $3.2 \mathrm{~m}$ rockbolt length (after Player et al. 2009; Player \& Cordova 2009) 
Table 1 Parameters of the modelling for three different dynamic tests (after Player et al. 2009; Player \& Cordova 2009)

\begin{tabular}{lllllll}
\hline $\begin{array}{l}\text { Length } \\
(\mathbf{m})\end{array}$ & $\begin{array}{l}\text { Bar } \\
\text { diameter } \\
(\mathbf{m m})\end{array}$ & $\begin{array}{l}\text { Loading } \\
\text { mass }(\mathbf{k g})\end{array}$ & $\begin{array}{l}\text { Impact } \\
\text { velocity } \\
(\mathbf{m} / \mathbf{s})\end{array}$ & $\begin{array}{l}\text { Borehole } \\
\text { diameter } \\
(\mathbf{m m})\end{array}$ & $\begin{array}{l}\text { Radial } \\
\text { stiffness } \\
(\mathbf{M P a} / \mathbf{m m})\end{array}$ & $\begin{array}{l}\text { Energy } \\
\text { dissipated } \\
(\mathbf{k J})\end{array}$ \\
\hline 2.3 & 22 & 1,964 & 6.7 & 45 & 1,010 & 19.7 \\
3 & 22 & 1,964 & 7.6 & 45 & 1,010 & 20.9 \\
3.2 & 22 & 1,964 & 7.9 & 45 & 1,010 & 30.5 \\
\hline
\end{tabular}

Table 2 Initial stiffness and viscous damping of the modelling for three different dynamic tests

\begin{tabular}{|c|c|c|c|c|}
\hline $\begin{array}{l}\text { Length } \\
\text { (m) }\end{array}$ & $\begin{array}{l}\text { Rockbolt } \\
\text { k (kN/mm) }\end{array}$ & $\mathrm{c}(\mathrm{Ns} / \mathrm{mm})$ & $\begin{array}{l}\text { Grout } \\
k(k N / m m)\end{array}$ & $\mathrm{c}(\mathrm{Ns} / \mathrm{mm})$ \\
\hline 2.3 & 10.42 & 12.10 & 15.24 & 0.25 \\
\hline 3.0 & 21.06 & 16.43 & 19.38 & 2.09 \\
\hline 3.2 & 7.87 & 16.88 & 20.50 & 2.51 \\
\hline & \multicolumn{2}{|c|}{$\underset{\text { ه2017 ltasca Consulting Group. Inc. }}{\boldsymbol{F L} \boldsymbol{A C} \boldsymbol{C}}$} & \multirow[t]{2}{*}{ Force Displa } & ment \\
\hline & 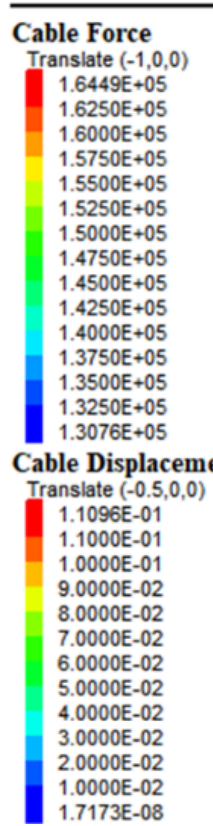 & & & \\
\hline
\end{tabular}

Figure 8 Example of final force $(N)$ and displacement $(m)$ profiles for $3.2 \mathrm{~m}$ rockbolt length

On the contrary, the behaviour of the grout has a limited influence on the final strength of the reinforcement element (Figure 7). The grout mainly influences the initial stiffness and the velocity profile during the process. Furthermore, the grout slightly improves the damping of the system.

If the grout is observed separately from the whole system, it reaches the yielding condition depending directly on the cohesive strength value. At this yielding point, the yielding condition is propagated partially or completely along the rockbolt due to the cohesive strength value used in the model.

According to the above, Figure 9 illustrates the yielding condition of the grout and the rockbolt for three different cohesive strength values at the same time interval of the simulation. The limit value for cohesive strength at the yielding condition in the numerical model is approximately $4.2 \times 10^{5}[\mathrm{~N} / \mathrm{m}]$ (Figure 9(c)). 
Nonetheless, the rockbolt reaches the yielding condition in some sections before the grout, even for low cohesive strength values. This generally agrees with observations made in laboratory-scale results of dynamic tests for threadbar (Player \& Cordova 2009; Player et al. 2009).

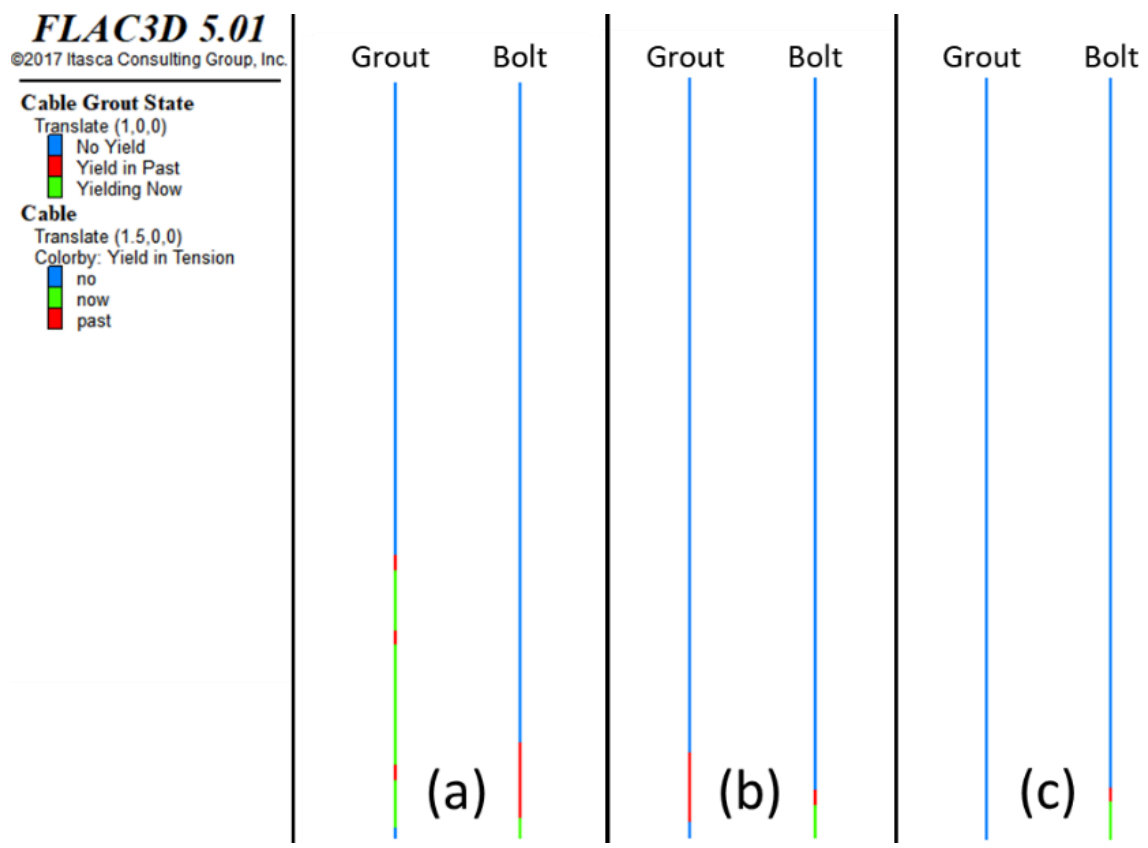

Figure 9 Yield condition for the grout and the rockbolt for three different cohesive strength values at the same time for $3.2 \mathrm{~m}$ rockbolt length. (a) $c_{g}=12.7(\mathrm{~N} / \mathrm{m})$; (b) $c_{g}=1.27 \times 10^{5}(\mathrm{~N} / \mathrm{m})$; and, (c) $c_{g}=4.2 \times 10^{5}(\mathrm{~N} / \mathrm{m})$

It should be noted that, as illustrated in Equation 7 (St John \& Van Dillen 1983), the grout friction angle in the numerical modelling was not considered. Some corrections have since been made by Bin et al. (2012) to the cohesive strength and friction angle for numerical purposes. Without these corrections, the model responds as expected according to experience in static conditions. Nevertheless, the behaviour of the grout under dynamic conditions is an area that is just recently being investigated, and for this reason, the results found and parameters used by numerical modelling should be taken as an approximation of actual behaviour.

Finally, it is also important to remember that the model represents the Canmet-MMSL dynamic test facility, whereas the comparative results belong to the WASM dynamic test facility. As was noted in Section 2, the results of tests from Canmet-MMSL for threadbar are restricted and not available for comparison. Thus, the comparison of the model at this point could be made only with the limited number of tests available in the literature for threadbar that have been done at WASM.

Furthermore, the choice of representing the Canmet-MMSL dynamic test facility was made with the intention of applying the model to other reinforcement elements in the future, due to its similarity with the future laboratory-scale dynamic testing facility to be built in Chile. It should also be observed that the results shown by the Canmet-MMSL facility and the WASM facility for reinforcement elements other than the threadbar, the results of which are restricted as noted above, are generally the same in terms of the response and curve shape within a measurable range (Player et al. 2008; Villaescusa 2012; Li \& Doucet 2012; Doucet \& Voyzelle 2012), even when both test facilities apply different concepts in their operation. In addition to the above, the model is adaptable and can be adjusted, if necessary, to extrapolate from and enhance the results of the future laboratory-scale dynamic testing facility to be built in Chile. 


\section{Conclusion}

The direct relationship among the propagation velocity of the reinforcement element, the dynamic increase of its yielding point, and its ultimate strength is appreciable through modelling. Consistent with the observations of Malvar and Crawford (1998), these variables, appreciable during the simulation time, have a distinctive influence on the limit and the oscillatory profile of the yielding condition in the reinforcement element.

For its part, grout plays a secondary role in the overall strength of the system, mainly initially influencing the system's stiffness and damping. However, research on grout in dynamic conditions related to reinforcement elements is an underexplored area, and, therefore, further study with major analysis of this particular component is required.

Nevertheless, numerical modelling results represent a valuable tool to visually support, enhance and illustrate the dynamic processes of reinforcement elements under laboratory-scale dynamic testing.

\section{Acknowledgement}

This research was financed by the 16CONTEC-65103 CORFO Innova Chile project under the 'Mejoramiento de las características dinámicas del perno helicoidal para la minimización de interferencias operacionales y riesgo asociado a la ocurrencia de sismicidad inducida por la minería subterránea' program.

The authors acknowledge the support of Corporación de Fomento de la Producción (CORFO), Compañía de Aceros del Pacifíco (CAP), and Advanced Mining Technology Center (AMTC). In addition, the authors thank CODELCO and CODELCOTech for the personal distinction through its Piensa Minería grant. Finally, Yesenia Marulanda is personally acknowledged for her contribution with necessary information for the conception and resolution of the problem.

\section{References}

Ansell, A 1999, Dynamically Loaded Rock Reinforcement, Institutionen för byggkonstruktion, Stokholm.

Ansell, A 2005, 'Laboratory testing of a new type of energy absorbing rock bolt', Tunnelling and Underground Space Technology, vol. 20, no. 4, pp. 291-300.

Bin, L, Taiyue, Q, Wang, Z \& Longwei, Y 2012, 'Back analysis of grouted rock bolt pullout strength parameters from field tests', Tunnelling and Underground Space Technology, vol. 28, pp. 345-349.

Cai, M \& Kaiser, PK 2018, Rockburst Support Reference Book, Volume I: Rockburst Phenomenon and Support Characteristics, MIRARCO Mining Innovation, Sudbury.

Doucet, C \& Gradnik, R 2010, 'Recent development with the Roofex bolt', in M Van Sint Jan \& Y Potvin (eds), Proceedings of the 5th International Seminar on Deep and High Stress Mining, Australian Centre for Geomechanics, Perth, pp. 353-366.

Doucet, C \& Voyzelle, B 2012, Technical Information Data Sheets, CanmetMINING, Ottawa.

Den Hartog, JP 1985, Mechanical Vibrations, Dover Publications, New York.

Hyett, AJ, Bawden, WF \& Reichert, RD 1992, 'The effect of rock mass confinement on the bond strength of fully grouted cable bolts', International Journal of Rock Mechanics and Mining Sciences \& Geomechanics Abstracts, vol. 29, no. 5, pp. 503-524.

Itasca Consulting Group 2012 Inc., FLAC3D, Itasca Consulting Group 2012 Inc., Minneapolis, https://www.itascacg.com/ software/flac3d

Kaiser, PK, McCreath, DR \& Tannant, DD 1996, Canadian Rockburst Support Handbook, Geomechanics Research Centre, Laurentian University, Sudbury.

Li, CC \& Doucet, C 2012, 'Performance of D-bolts under dynamic loading', Rock Mechanics and Rock Engineering, vol. 45, no. 2, pp. 193-204.

Malvar, L \& Crawford, JE 1998, 'Dynamic increase factors for steel reinforcing bars [C]', Proceedings of the 28th Department of Defense Explosives Safety Board Seminar, Department of Defense Explosives Safety Board, Alexandria.

Nilsson, C 2009, Modelling of Dynamically Loaded Shotcrete, Royal Institute of Technology, Stokholm.

Player, JR \& Cordova, M 2009, Dynamic Threadbar Test at WASM, internal report for CODELCO - El Teniente Mine, Western Australian School of Mines, Kalgoorlie.

Player, JR, Thompson, AG \& Villaescusa, E 2008, 'Dynamic testing of reinforcement systems', Proceedings of The 6th Internacional Symposium on Ground Support in Mining and Civil Engineering Construction, International Society for Rock Mechanics and Rock Engineering, Lisbon.

Player, JR, Villaescusa, E \& Thompson, AG 2004, 'Dynamic testing of rock reinforcement using the momentum transfer concept', in E Villaescusa \& Y Potvin (eds), Proceeding of the Fifth International Symposium on Ground Support, A.A. Balkema, Rotterdam, pp. 327-339. 
Player, JR, Villaescusa, E \& Thompson, AG 2009, 'Dynamic testing of threadbar used for rock reinforcement', in M Diederichs \& G Grasselli (eds), Proceedings of RockEng09: Rock Engineering in Difficult Conditions, Paper 4030, Canadian Institute of Mining, Metallurgy and Petroleum, Westmount.

Rao, SS \& Yap, FF 2011, Mechanical Vibrations, Prentice Hall, Upper Saddle River.

Rayleigh, L 1877, Theory of Sound, Dover Publications, New York.

St-Pierre, L 2007, Development and Validation of a Dynamic Model for a Cone Bolt Anchoring System, Master's thesis, McGill University, Montreal.

St John, CM \& Van Dillen, DE 1983, 'Rockbolts: a new numerical representation and its application in tunnel design', The 24th US Symposium on Rock Mechanics (USRMS), American Rock Mechanics Association, Alexandria.

Tannant, DD, Brummer, RK \& Yi, X 1995, 'Rockbolt behaviour under dynamic loading: field tests and modelling', International Journal of Rock Mechanics and Mining Sciences \& Geomechanics Abstracts, vol. 32, no. 6, pp. 537-550.

Thompson, AG, Player, JR \& Villaescusa, E 2004, 'Simulation and analysis of dynamically loaded reinforcement systems', in E Villaescusa \& Y Potvin (eds), Proceeding of the Fifth International Symposium on Ground Support, A.A. Balkema, Rotterdam, pp. 341-355.

Villaescusa, E 2012, Static and Dynamic Laboratory Testing of Rock Reinforcement - El Teniente Mine, Western Australian School of Mines, Kalgoorlie.

Wu, R, Oldsen, J \& Lamothe, M 2010, 'The Yield-Lok bolt for bursting and squeezing ground support', in M Van Sint Jan \& Y Potvin (eds), Proceedings of the Fifth International Seminar on Deep and High Stress Mining, Australian Centre for Geomechanics, Perth, pp. 301-308.

Yi, X \& Kaiser, PK 1992, 'Stress in dynamically loaded rockbolts with rubber and wood cushions', in PK Kaiser \& DR McCreath (eds), Proceedings of the International Symposium on Rock Support: Rock Support in Mining and Underground Construction, A.A. Balkema, Rotterdam, pp. 683-691.

Yi, X \& Kaiser, PK 1994a, 'Elastic stress waves in rockbolts subject to impact loading', International Journal for Numerical and Analytical Methods in Geomechanics, vol. 18, no. 2, pp. 121-131.

Yi, X \& Kaiser, PK 1994b, 'Impact testing for rockbolt design in rockburst conditions', International Journal of Rock Mechanics and Mining Sciences \& Geomechanics Abstracts, vol. 31, no. 6, pp. 671-685. 